\title{
Mothering at a distance and disclosure of maternal HIV to children in Kingston, Jamaica
}

\section{Gayle Clifford, Gill Craig and Christine McCourt}

\section{Authors and affiliations:}

Authors: Gayle Clifford (1), Gill Craig (2), Christine McCourt (1) (in this order)

Establishments: (1) City, University of London

(2) University of Hertfordshire; City, University of London

Corresponding Author: Gayle Clifford, gayle.clifford.1@city.ac.uk and gaylecliffords@yahoo.com

Date of submission: 31.09.2017

\begin{abstract}
:
Existing guidelines (WHO, 2011) advise caretakers and professionals to disclose children's and their caretakers' HIV status to children, despite a lack of evidence concerning the potential implications in resource-constrained settings. Our research uses feminist Interpretative Phenomenological Analysis (IPA) to explore the experiences of HIV positive mothers in Kingston, Jamaica, focusing on their lived experiences of talking to their children about maternal HIV.
\end{abstract}

This paper will focus on the concept of mothering at a distance and how this presents additional challenges for HIV positive mothers who are trying to establish emotional closeness in relation to talking to their children about their HIV. Using Hochschild's concept of emotion work and examples from the interviews, we highlight the difficult contexts informing women's decisions when negotiating discussions about their HIV. Women may choose full, partial or differential disclosure or children may be told their mother's HIV status by others. Disclosure policy, we argue, reflects Anglo-Northern constructions of the family and parenting which may not adequately reflect the experiences of poor urban mothers in low and middle income countries. We argue that policy needs to recognise culturally-specific family formations, which, in Jamaica includes absent fathers, mothering at a distance and mothering non-biological children. This article reflects on the experiences of an under-researched group, poor urban Jamaican women practising mothering at a distance, using a novel methodological approach (IPA) to bring into relief unique insights into their lived experiences and will contribute to the global policy and research literature on HIV disclosure.

Keywords: Feminist IPA, HIV disclosure, mothering, emotion work

Compliance with Ethical Standards: Informed consent was discussed with and obtained from all participants. Ethical approval was received from two review boards in Jamaica (University of the West Indies, Faculty of Medical Science and the Jamaican Ministry of Health) and one in the UK (City, University of London, School of Health Sciences). Pseudonyms are used throughout. 


\section{Introduction}

This paper explores the relationship between different familial formations, particularly mothering at a distance, and how these formations may influence maternal disclosure of HIV to children who are HIV negative in the Jamaican context. We define mothering at a distance as the experience of mothering children who live with their father or other family members overseas or elsewhere in Jamaica.

Existing guidelines (e.g., WHO, 2011:12), advise caretakers to disclose children's and their caretakers' status to children, despite limited evidence on the disclosure experiences of caretakers in resource-constrained settings such as the Caribbean. In high income settings, disclosure has been shown to have a positive impact on maternal physical health (Chaudoir and Quinn, 2010), mental health (Wiener, Battles and Heilman, 1998), to increase social support (Letteney, 2006; Wiener et al., 2007) and encourage closer family relationships (Tenzek et al., 2013). Research in low and middle income countries recommends culturally specific support to disclose but does not make clear what this means in different contexts (e.g., Obermeyer, Baijal and Pegurri, 2011; Qiao, Li and Stanton, 2011; Rochat et al., 2011; Krauss et al., 2012). Although Rochat and colleagues (Rochat, Mkwanazi and Bland, 2013; Rochat et al., 2014, 2015, 2016, 2017) provide a detailed model of a maternal disclosure intervention in the South African context, nothing similar exists in Jamaica or the Caribbean.

In 2017, we found 23 articles (referring to 16 studies) on disclosure of parental or caregiver HIV to their children (from the perspective of parents/caregivers) in peer reviewed journals in low and middle income countries in Africa (22) and one study in the Caribbean (Conserve et al., 2014). Moreover, only 2 studies (producing 6 articles) focussed on the experiences of mothers specifically (Rochat, Mkwanazi and Bland, 2013; Conserve et al., 2014; Rochat et al., 2014, 2015, 2016, 2017). Of the 23 articles we identified, only those by Rochat and colleagues clearly specify that the children were HIV negative; the other articles include children who are a mixture of HIV positive and HIV negative or whose HIV status is unknown.

The earlier disclosure literature (e.g., Armistead et al., 2001; Tompkins, 2007; Moore, Kalanzi and Amey, 2008) presented disclosure as a binary (disclosure/non-disclosure), but more recent research (e.g., Madiba and Matlala, 2012; Kyaddondo et al., 2013; Tiendrebeogo et al., 2013; Muparamoto and Chiweshe, 2015) suggests disclosure is a more complex phenomenon. For example, some authors distinguish between: 'full' and 'partial' disclosure (e.g., De Baets et al., 2008; Gachanja, 2014; Gachanja, Burkholder and Ferraro, 2014a, 2014b; Gachanja and Burkholder, 2016); 'brief' 
and 'explicit' disclosure (Conserve et al., 2014); or 'told', 'not told' and 'thought to have guessed' (Nam et al. 2009). Similarly, Kyaddondo et al. (2013) write of 'non-verbal' disclosure methods such as leaving medication around the house, asking children to collect medication or accompany parents to treatment centres. Moreover, the proliferation of studies reporting on the benefits of disclosure (e.g., Thorne, Newell and Peckham, 2000; Dane, 2002; Nostlinger et al., 2004; Xu, 2007; Geiselhart, Gwebu and Krüger, 2008; Rwemisisi et al., 2008; Nam et al., 2009; Thomas, Nyamathi and Swaminathan, 2009; Zhou et al., 2013) and recommendations on interventions to increase the rates of disclosure (e.g., WHO, 2011; Krauss et al., 2012) implies that most authors consider parental disclosure desirable.

We aim to explore these assumptions further by bringing into relief women's lived experiences as mothers with HIV using feminist Interpretative Phenomenological Analysis (IPA). We aim to shed light on the complexities of disclosure and the disclosure continuum (Allison and Siberry, 2015) in the context of mothering in Jamaica. These experiences can inform policy related to disclosure of maternal HIV to their HIV negative children and ensure it is more culturally appropriate to Jamaican and Caribbean contexts.

\section{Contextualising HIV and mothering in Jamaica}

Jamaica demonstrates features of a generalised and concentrated epidemic (PAHO/WHO, 2010) with approximately $1.8 \%$ of the adult population infected with HIV (Jamaican Ministry of Health, 2014). Although the reported total number of men living with HIV (54\%) is greater than the total number of women living with HIV (46\%) in Jamaica, the gap is narrowing (Jamaican Ministry of Health, 2014 ${ }^{1}$ ). Bearing in mind the high cultural value placed on motherhood in Jamaica (Ellis, 1986; Silva, Smith and Alexander, 2013) and that the majority of women's diagnoses of HIV occur during antenatal testing, a significant proportion of women with diagnosed HIV are also mothers. The dual impact of a disease which is sexually transmitted, carrying connotations of promiscuity (Sontag, 1991) and the fear of illness and death, combine to make HIV an emotive and complex subject for mothers to address with their children. Jamaica remains in many ways a patriarchal society: contradictions and complexities of mothering abound within a structure of (predominantly) male power and violence; yet the mother's role carries power and status and mothers are expected to be independent and resourceful, providers and protectors (Ellis, 1986; Silva, Smith \& Alexander, 2013).

\footnotetext{
${ }^{1}$ Reporting on the period 2009-2012.
} 
Moreover, whereas in Anglo-Northern contexts images of the nuclear family dominate as the norm, this is not the case in many resource-constrained contexts. For example, in Jamaica and other countries, child shifting is common, that is, the practice of 'shifting' childrearing responsibilities, in the short or long term, from biological parents to family members or friends (Russell-Brown, Norville and Griffith 1997). Child-shifting is often associated with transnational mothering or mothering across borders (Hondagneu-Sotelo and Avila, 1997; Parrenas, 2001; Phoenix, 2010), which generally occurs when mothers migrate to another country, usually for financial reasons, to take up paid employment. It is more common within low income families who have fewer resources to provide options in challenging times and a child may be shifted multiple times from relative to relative. Evans and Davies (1997) estimated that 15 to 30 percent of Caribbean children are brought up by relatives or neighbours. Child shifting may occur where the biological parent dies or migrates, during the mother's pregnancy or birth of a sibling, or in cases of new relationships where the child is not wanted. It also takes place in cases where a relative has no children of their own or is seen as being able to provide a better life for the child (Barrow, 1996; Evans and Davies, 1997). Russell-Brown, Norville, and Griffith (1997) write that children are shifted because mothers believe that it is in their best interests and that, rather than indicating a lack of love, the decision represents enormous maternal sacrifice. Transnational or distant mothers, although unable to be physically present and provide emotional care, are working, often as sole breadwinners, to provide materially for their children (Phoenix, 2010) and are therefore caring for their children to the best of their ability at that time.

\section{Methodology and research process}

\section{Methodology}

For this research we used feminist Interpretative Phenomenological Analysis (IPA). IPA is a qualitative research methodology (Smith, 1996) which is hermeneutic, phenomenological and idiographic and provides rich detail which illuminates lived experience. We employ feminist reflexivity to highlight issues of power and difference (Burman, 2006). Additionally, given that our interpretation of the women's accounts will be affected by our own views and experiences as 'outsider' researchers (Mullings, 1999; Brodsky and Faryal, 2006; Dwyer and Buckle, 2009) in the Jamaican context, we worked to acknowledge and reflect on the impact of our positioning on the research process. 
This approach complements the key elements of IPA, particularly the detailed focus on individual experience and sense-making (Smith, Flower and Larkin, 2009) and the emphasis on interpretation by both the researcher and the participants, the 'double hermeneutic' (Smith and Osborn, 2003). Combining a feminist approach with IPA (Leve, Rubin and Pusic, 2011) helps to deepen our understanding of gender inequalities by recognising difference and power imbalances and acknowledging the impact of wider structural factors on both the research process and women's lived experiences. For example, Leve, Rubin and Pusic (2011: 123), exploring women's experiences of cosmetic surgery, attempted to address the tension between individual experience (or "voice-centred perspectives", e.g., Tarule, 1996) and wider structural factors (or culturecentred perspectives $e, g$., Bordo, 1997), which influence women's choices, by situating women's narratives within broader social, cultural and political contexts. Similarly, we aimed to contextualise women's narratives in the broader social and economic context of mothering in Jamaica and the experience of poverty: contexts which both shape and inform women's decisions around disclosure. Although IPA has not yet been used extensively in resource-constrained settings, its focus on lived experience and interpretation make IPA an effective analytical tool for work with disadvantaged groups.

Given the assumed emotional nature of talking about HIV we also drew on Hochschild's concept of emotion work $(1979,1983)$. Hochshild proposed the concept of emotion work to describe the (often unrewarded and unrecognised) work that individuals carry out to manage their own and other people's emotions. Emotion work refers "to the act of trying to change in degree or quality an emotion or feeling" (Hochschild, 1979:561). Emotion work explores not only how people think and feel about an experience, but how they think they should feel and how they think others think they should feel, as well as what they do about any disconnects among these feelings (Hochschild, 1983). We will refer to this concept in relation to the emotion work which the women we interviewed performed in relation to their decisions to disclose their HIV status to their children.

\section{Methods}

The experiences presented here are taken from interviews with 15 poor, urban, HIV positive mothers, in Kingston, Jamaica in 2012-2013, focusing on their lived experiences of talking to their children about maternal HIV. Interviews lasted 30-70 minutes and took place at a local HIV clinic (12 interviews) or the office spaces used by a local HIV NGO ( 3 interviews). The researcher relied on clinicians to identify women according to the following inclusion criteria: HIV positive women aged over 18; and the mother of at least one HIV negative child aged over 10 years. An additional criteria was that women were deemed comfortable discussing their HIV; this may have affected 
clinicians' decisions about who to involve. The issue of gatekeepers in recruiting participants into studies is well rehearsed (e.g., Shenton and Hayter, 2004).

Due to the idiographic focus of IPA and the depth of analysis required, sample sizes are usually small (Smith, Flower and Larkin, 2009); the interviewer intended to stop after about 12 participants, but continued to 15 to honour appointments made by clinicians. Participants received compensation for their participation (drinks, snacks and bus fare). Five women declined to participate: two due to work or personal commitments, one was uncomfortable with the use of the audio recorder and two agreed to participate but did not attend. The interviewer could not ascertain whether these were genuine reasons or polite excuses, but felt reassured that women did not feel pressurised to participate and were able to opt out of the study.

The interviewer (Clifford, one of the authors) conducted the interviews using standard English. Participants replied using standard English, Jamaican Patois or a combination. Interviews were transcribed by a Jamaican transcriber using a standardised system (Cassidy and Le Page, 1980) of written Jamaican Patois. For ease of reading in this paper we present the women's words in standard English (translated by the interviewer). The interviews were semi-structured, beginning with general questions about the women's diagnoses, relationship with children and disclosure issues. The interviewer then followed up on what the women said or encouraged interviewees to continue by using silence or short prompts. Interviews sought to work through the events in the women's lives which they perceived to be significant in terms of communicating about their HIV status with their children; women were considered to be the 'experts' of their experiences. The interviewer attempted to clarify meanings, mirrored the women's word choices, asked open questions and allowed participants time and space to answer questions (Sin, 2010).

\section{Analysis}

Interview transcripts were analysed in detail to elicit key experiential themes, following Smith, Flowers and Larkin's analysis guide which proposes working case-by-case to carry out careful lineby-line analysis and identification of themes, "emphasising both convergence and divergence, commonality and nuance" (2009:79-80). We used exploratory, linguistic and conceptual notes which were then developed into themes linked to Hochschild's concept of emotion work (1979, 1983). Particular attention was paid to reasons given for choices in relation to maternal disclosure and how these related to concepts of mothering, as well as to comments highlighting the broader impact of community and social factors. We also focused on apparent contradictions within interviews, times where a participant revisited the same idea, and concepts which appeared difficult for the participant to express. We then combined cases to create a "full narrative", with "detailed 
commentary" (Smith, Flower and Larkin, 2009:79-80), which leads the reader thematically through the interpretation and our reflections on the process.

\section{Findings: Participant demographics}

Women ranged in age from 32-57 years and had between 1 and 4 children aged 2-35 (including at least one seronegative child aged over 10 years). Participants were diagnosed 6 months to 17 years prior to interviews. Five women described themselves as married or living with their partner, one as widowed, 9 women said they were single or in a 'visiting' relationship, where they were responsible for childcare and income generation. As is common in Jamaica, the majority of the women had multiple 'babyfathers', a term which implies a merely biological relationship (Turner, 2006). Six women were unemployed, 4 had occasional employment (such as selling snacks in the market on a Saturday or occasional domestic work), 4 were employed and the employment status of one participant is unknown. As little is known about HIV positive mothers and disclosure in the Jamaican context, this sample can be considered to be broadly homogenous within IPA (Smith, Flower and Larkin, 2009).

At the time of the interviews, 7 of the 15 women had at least one child living (or in the case of adult children, who had lived for a significant period) in a different part of Jamaica and being cared for by extended family, often grandmothers. Two of these women had their oldest child living 'abroad', with the child's biological father or paternal grandparents. Six women had told some children but not others about their HIV (differential disclosure); of these 5 were practising mothering at a distance. Additionally, two of the women were caring for a non-biological child.

\section{Approaches to Disclosure}

Our study highlighted different contexts informing disclosure and approaches including differential, indirect, and disclosure by others, as well as non-disclosure. Compared to mothers whose children all lived with them, mothers practising mothering at a distance were more likely to practice differential disclosure and more likely to experience their children being disclosed to by others. Using quotes to illustrate their experiences, we now present four dominant maternal disclosure experiences of HIV positive Jamaican mothers who practised mothering at a distance.

\section{Differential disclosure}

Maria compared the close relationship she had with her younger two daughters (who lived with her 
and whom she had told about her HIV) with the more distant relationship she had with her older daughter:

[...] It's just that she is sentimental and because I had to send her away wid [with] her dad from then, and I knew the child she was before she left here she was so cry-cry. Everything she cry about and even now she still cry. So I was like "No, I'm not gonna tell her. Why should I tell her anything? And she is not even here?" and so that's why I decided not to tell her. It's not like she is here and she is gonna see me going through the phases and getting sick and have to come here [to the clinic] and she would want to know "Why you going there, mom?" and ask questions. No, she is not here so I'm like I don't need to tell her.

Maria dismissed her daughter's emotions with words such as 'cry-cry' and 'sentimental' and decided specifically to exclude her from knowing about her status, instructing her other daughters not to tell her. There may be a clue in the words "because I had to send her away wid her dad", and she later referred to the "bond" she shared with her other two daughters. Perhaps she felt that the lack of a close relationship with her daughter was something outside her control, and that, without that history and bond, she was unable to navigate the emotional minefield of talking to her geographically distant daughter about her HIV status. Differential disclosure was identified by Dane (2002) as associated with the age of children, but in the Jamaican context it seems to be more often associated with the challenges of maintaining emotional closeness while mothering from afar.

\section{Non-disclosure: The challenges of preserving the mother-child 'bond' across distance}

Susie's daughter, her only child, was brought up in rural Jamaica by Susie's mother and twin sister, while Susie worked in Kingston in order to send money to them. She expressed sadness and regret at allowing her daughter to grow up with her mother, reflecting that, although it made practical and economic sense for them as a family, even at the time she had had misgivings:

[...] my mother said to me, send her down and I will take care of her for you./ - And I said to her "No, Mama". I didn't want to do it. I didn't want to do it because you're not going to... bring up the child- / - to know me and have a bond.... I went to this lady next door and said to the lady "You know that my mother wants me to send the baby to the country?" She said "Don't send your daughter down there because you will regret it"./And so said, so done. When her father came to Jamaica, she preferred her father over me.

Susie felt that she and her daughter did not have an emotional bond as a result of her being brought up by Susie's mother and twin sister. She touches here on the long standing racism inherent within Jamaican society, where those with lighter skin are treated more favourably than those with darker skin (Leo-Rhynie, 1996): 
Mothering at a distance and disclosure of maternal HIV in Kingston, Jamaica Clifford, Craig \& McCourt ...You see, the bond that me and my daughter have?-should have? We don't have it./[...] I believe- I don't know if I'm blaming my family, but I feel that ... they didn't want me to have much to do with her. They feel like she's too good for me./[...] She's a pretty girl. Shand because I have dark skin and my twin sister is brown-she's brown, you understand me? / She [my daughter] doesn't call me mami, she calls my sister mami.

She highlights the loss of her relationship with her daughter, where her daughter fails to acknowledge even their biological relationship. Susie goes on to describe a time when she tried to fulfil a traditional maternal role, advising her daughter to abstain from sex and focus on her studies:

'Cause I remember one day, my mother said something to me about - she's with this guy and blah blah blah and I called and said to her [my daughter]: "Now is not the time for boyfriends, now is the time for education./ As a matter of fact, I can't tell you not to have a boyfriend but don't have sex because once you start having sex, it will complicate your education". And then her remarks to me were that I- I wanted a- how did it go?- I'm not perfect and I want a perfect daughter. Because her father said to her that she- he never wanted me and I chased after him./You understand me? So that was the remarks. So that's why I say even if I was on my deathbed I don't think I could tell her.

This conversation made Susie feel that her character and choices were being attacked and that her daughter felt closer, not only to Susie's mother and sister, but also to Susie's ex-partner (her daughter's father). Susie believed that she acquired HIV from her daughter's father and the perceived unfairness and lack of understanding illustrated by this conversation made Susie feel certain that she could never, even on her 'deathbed', tell her daughter that she had HIV.

\section{Indirect disclosure: the grey areas of knowing}

Only one mother, Tina, had herself talked to children who did not live with her about her HIV: "Because I think umm all my children should know". At the beginning of the extract below, Tina implied she had told all her children; it was only when questioned further that she stated she had only fully told the older two. Despite living apart from her older three children, she devised a way to tell her third child, by enrolling him in a programme run by a local NGO specifically designed for the children of HIV positive mothers:

Gayle: And what about your children?

Tina: Yeah.

Gayle: All of them?

Tina: No, the two first one[s]. Well, the third one because umm, I am having [h]im in some ummm - with [an HIV NGO] .......I have him [...] [at] some-something that-that-that will teach him about HIV./ So I - I haven't spoke him that I'm HIV positive, but [...]/Suh umm, maybe, maybe he knows because when he went there he saw friends and those 
friends are child[ren] of a HIV positive parent.

The extract above is quite stilted and illustrates the difficulties she felt in telling her third child. Tina was active in several NGOs, evident sometimes in the words she used and also possibly in some of the concepts she embraced. Her expressed desire to tell her children seemed to be influenced by NGO encouragement of family disclosure: "Because ummm, I was kind of jealous when I heard everybody say that they had disclosed to their children, you know".

Pollard (2013:153) laments the physical absence of mothers and contends that this deprives their children of crucial "emotional support and security". That this can be the case, even when the mother is in Jamaica, but working in Kingston, is acknowledged by Tina in the extract below. Tina referred to the financial responsibility she felt towards her children, but she also identified the importance of her physical presence and acknowledged that she was not able to provide that:

I would visit them. And the first two, I give them everything. Ummm, before meeting the second baby father when I was here in Kingston, I work, I work at [a dry cleaners], I do evening jobs, I make sure that they got money every week to go to school, I make sure that they got everything. Just one thing they need that was me being there for them, I mean like literally being there...

Here Tina summed up the challenges facing many low income Jamaican mothers, who must make decisions between providing for their children financially and being there for them emotionally. Working to be a visibly 'good' mother in the context of geographical separation is a huge challenge for women whose children live with others for financial, practical or other reasons. Mothering at a distance affects both HIV positive and HIV negative mothers, but presents additional challenges for HIV positive mothers who are trying to establish emotional closeness prior to talking to their children about their HIV. The women worked to manage feelings of guilt and blame as well as other interconnected and often uncomfortable feelings: loss, anger, sadness, fear, anxiety, love. These feelings are complicated by family dynamics; mothers and children exist within a complex web of familial relationships, with siblings/half-siblings, partners (who may also be fathers/step fathers), grandparents, aunts, uncles, cousins as well as relationships with teachers, neighbours and others within the wider community.

\section{Disclosure by grandmothers}

A further challenge for mothers living apart from their children occurs when their caregiver, often the maternal grandmother, discloses the mother's status to her child. These grandmothers may feel that they have rights conferred by their relationship and as a result of their caregiving role, though this view is not always shared by their daughters. Disclosure of maternal HIV by maternal grandmothers can complicate the relationship between mothers and their children and can lead to 
additional emotion work for mothers who were not ready to talk about their HIV with their children and who may feel angry or betrayed by their own mothers.

Laura mentioned some of the factors that led to her sons sometimes living with her mother, Barbara.

Laura: Oh, the other one is getting rude and she [my mother] can't manage him so I have him now with me. [...]

Gayle: Okay. And how is that?

Laura: Well it's ok. They normally back and forth living with me now and den [then] but because um, they not gonna be supervised like how I want them to, that's why they stay with her because [I] am an only child so they are a company [for her] but the smaller one is living with me now. Ye, ye he's ok but he visits [her] on weekends.

For Laura, this is a flexible, fluid arrangement that shifts according to the needs of individual family members. However, although Laura considered talking to her sons about her HIV to be her responsibility as her children's mother, Barbara disclosed Laura's status to her oldest son whilst Laura was in hospital with HIV-related complications. Laura's interview is characterised by avoidance and control, so it is not surprising that she would feel angry that her mother took this task from her or that she would avoid detailed discussion of it with her mother. However, it is also easy to imagine the challenges Barbara would have faced, caring for her two grandsons while Laura was in hospital.

Laura: Well at first...um ... and even now - I-I - am upset. I was upset about it.[...] but I - I wish for her was to wait and let me tell who I wanted to tell. 'Cause she has now told my bigger son and I think that she should have waited and let me sit and talk to him about it. I was upset with her about that whole situation. [...] So I [...] said "Mom, you should have allowed that to be done by me. You should not have done that."

Gayle: And what did she say?

Laura: She didn't say anything about it. She just bypassed it as if it's nothing.

This extract highlights some of the communication challenges faced by families affected by HIV, particularly where other family members are involved in childcare responsibilities.

Although Johnett began by saying that she told her eldest son, when the interviewer asked for details she said that, in fact, her mother had told him:

Well, I didn't really tell him you know. My mother told him....My mother told him but he still hasn't asked me about it.

She attributed this to the close relationship her mother had with her children, which she believed was closer than the relationship she herself had with them:

... They have a good relationship, better than me. Because my mother grew him [brought 
him up] from when he was ten months old. /You understand? Even my daughter too. So they have a closer relationship with my mother-with their grandmother-than with me. Ye./[...]He is not really going to say it to me.

The combination of their more distant relationship and the fact that the information came from his grandmother made it more difficult for Johnett and her son to discuss her status. However, her son mentioned it to her obliquely and she took this opportunity to reassure him that she is taking care of her health:

[...]- the only thing I realised, although he didn't tell me - that my mother must have told him? He said to me "You're sick, you know? You shouldn't drink alcohol or mess yourself up" [...] I said "I know I shouldn't drink alcohol and anyway you know I don't drink alcohol. [...] You know that if I do anything I won't mess up my body, mess up myself, do a whole heap of work... and all that".

\section{Discussion}

Our results have brought into relief the different familial formations which are typical of the Caribbean, including mothering at a distance, which may influence whether and how women communicate their HIV status to their children. The examples we have quoted indicate that mothers do not always live with their children but practice mothering at a distance. Historically, in post war Anglo-Northern contexts, mother-child separation has been viewed negatively and as having a detrimental impact on children's emotional development (Bowlby, 1969). However, in the Jamaican context, child-shifting is common (Evans and Davies, 1997; Russell-Brown, Norville, and Griffith, 1997). Child-shifting alters the concept of what it means to be a good mother, from one who is physically present and provides, amongst other things, day to day emotional support, to one who is geographically distant and provides financial support. The contrast can be seen with the intensive mothering concept, where mothers are physically present and provide round-the-clock child-centred care (Hays, 1996). We suggest that policy to disclose may be predicated on AngloNorthern constructions of the nuclear family which assumes mothers live with their children, are partnered with children's fathers, and are the major caregivers rather than, additionally, breadwinners. Policies may therefore fail to theorise the impact on disclosure of different familial formations and mothering roles and experiences in the Caribbean. However, some authors, writing about Botswana (Geiselhart, Gwebu and Krüger, 2008) and South Africa (Palin et al., 2009) draw attention to different family configurations and the importance of extended family involvement in HIV programmes. 
Given disclosure is assumed to be positive and beneficial, not disclosing may be construed negatively and reflect badly on women's competency as mothers. However, in our study HIV positive mothers practising mothering at a distance carried out considerable emotion work to preserve a positive maternal identity and present themselves as 'responsible' mothers (Lupton, 2011) in order to protect their maternal identity and their relationships with their children. They worked to maintain the emotional closeness expected by society as proof of a close mother-child bond, despite the reality of physical distance and infrequent contact, challenges which were compounded by the difficulties of managing HIV. Mothers were aware that they stood to be doubly judged, both for their HIV status and for living apart from their children. Pressure to disclose may also stand as an additional judgement given the policy imperative. Mothering at a distance is an emotionally complex experience, full of challenges and contradictions. Many women presented the decision to have their children live apart from them as either outside their control (usually decided by their own mother or by the child's father) or as in their child's best interests (such as taking up the opportunity to live overseas or remaining in rural areas with relatives while their mother worked in the city and sent money for their care). Some women harboured regrets, whilst others were more pragmatic; for some women it was a short term or fluid arrangement whereas for others, it was longer term. However, in all cases, the physical distance between mothers and their children made disclosure of maternal HIV to those children practically and emotionally more challenging than to the children who lived with their mothers. Situations where other family caregivers (usually maternal grandmothers) disclosed maternal HIV to their grandchildren without the mother's consent added another layer of complexity to the emotion work that these women performed.

\section{Policy implications}

We will now discuss the implications of our findings for policy. Our research suggests that existing guidelines on disclosure to children (e.g., WHO 2011), designed to support professionals working with HIV affected families, would benefit from considering factors that women identified as important (i.e., recognising and respecting local concepts of maternal identity and supporting relationship building within the family rather than directly promoting disclosure). Recognition of the complexities of women's lives and the tensions involved in talking to children about HIV would respect women's choices, strengthen family relationships as well as patient-professional relationships, and ultimately improve patient health. Policy also needs to recognise the risks associated with disclosure of HIV to both mother and child in the wider context of structural inequalities, gender violence, migration, and poverty. 


\section{Future research}

In this study, we did not interview children so have not researched the impact of disclosure from children's perspectives; future research could focus on children's views. Further research might additionally explore the role of maternal grandmothers, given their frequent childcare responsibilities. Research involving women in rural areas and other Caribbean countries is also needed, as, to date, the only published research on maternal disclosure in the Caribbean comes from Haiti (Conserve et al., 2014).

\section{Conclusion}

This study has used a novel approach, feminist IPA, to bring into relief the complex factors influencing maternal disclosure of their HIV status to HIV negative children. The results suggest existing policy recommendations to caretakers to disclose to children may underestimate the complexity of family formations in resource-constrained countries, including child shifting, multiple carers and mothering at a distance, factors which shape and determine whether and how mothers' status is divulged to children.

The disclosure experiences of HIV positive mothers who perform mothering at a distance help to extend our understanding of the spectrum of disclosure experiences that exist in the Jamaican context and the range of sophisticated emotion work which the women carry out in order to manage their own and their children's emotions concerning maternal HIV. Disclosure policies which reflect Anglo-Northern constructions of mothering and parenting may fail to adequately theorise the experiences of poor urban mothers in low and middle income countries such as Jamaica. More nuanced policy would recognise the lived experiences of HIV positive women and be sensitive to the factors which impact on women's decisions, including culturally-specific family formations.

\section{References}

Allison, S. and Siberry, G. (2015) 'National Institutes of Health investment in studies of HIV disclosure to children.', AIDS, 29(March), pp. S109-S118.

Armistead, L., Tannenbaum, L., Forehand, R., Morse, E. and Morse, P. (2001) 'Disclosing HIV status: Are mothers telling their children?', Journal of Pediatric Psychology, 26(1), pp. 11-20. doi: 10.1093/jpepsy/26.1.11.

Barrow, C. (1996) Family in the Caribbean: themes and perspectives. Kingston, Jamaica: Ian Randle Publishers. 
Bordo, S. (1997) 'Material girl: The effacements of postmodern culture', in Lancaster, R. and di Leonardo, M. (eds) The Gender/Sexuality Reader: Culture, History, Political Economy. London: Routledge, pp. 335-358.

Bowlby, J. (1969) Attachment and loss, Vol. 1: Attachment. New York: Basic Books.

Brodsky, A. E. and Faryal, T. (2006) 'No matter how hard you try, your feet still get wet: Insider and outsider perspectives on bridging diversity', American Journal of Community Psychology. doi: 10.1007/s10464-006-9015-x.

Burman, E. (2006) 'Emotions and reflexivity in feminised education action research', Educational Action Research, 14(3), pp. 315-332. doi: 10.1080/09650790600847636.

Cassidy, F. and Le Page, R. B. (1980) Dictionary of Jamaican English. Cambridge: Cambridge University Press.

Chaudoir, S. R. and Quinn, D. M. (2010) 'Revealing concealable stigmatized identities: The impact of disclosure motivations and positive first- disclosure experiences on fear of disclosure and wellbeing.', Journal of Social Issues, 66, pp. 570-584. doi: doi:10.1111/j.1540-4560.2010.01663.x.

Conserve, D. F., Eustache, E., Oswald, C. M., Louis, E., King, G., Scanlan, F., Mukherjee, J. S. and Surkan, P. J. (2014) 'Disclosure and Impact of Maternal HIV+ Serostatus on Mothers and Children in Rural Haiti', Maternal and Child Health Journal, 18(10), pp. 2309-2315. doi: 10.1007/s10995013-1375-x.

Dwyer, S. C. and Buckle, J. L. (2009) 'The Space Between: On Being an Insider-Outsider in Qualitative Research', International Journal of Qualitative Methods, 8(1), pp. 54-63. doi: $10.1177 / 160940690900800105$.

Ellis, P. (1986) Women of the Caribbean. London: Zed Books Ltd.

Evans, H. and Davies, R. (1997) 'Overview of issues in Childhood Socialisation in the Caribbean', in Roopnarine, J., L., and Brown, J. (ed.) Caribbean Families: Diversity among Ethnic Groups. Greenwich, CT: Ablex., pp. 1-24.

Gachanja, G. (2014) 'A couple's marital disharmony and its psychological effects on their children during the HIV disclosure process in Kenya', PeerJ. doi: 10.7287/peerj.preprints.419v1.

Gachanja, G. and Burkholder, G. J. (2014) 'HIV-Positive Parents' Accounts on Disclosure Preparation Activities in Kenya', Journal of social,Behaviour and Health Science, 8(1), pp. 18-37. doi: 10.5590/JSBHS.2014.08.1.02.

Gachanja, G. and Burkholder, G. J. (2016) 'A model for HIV disclosure of a parent's and/or a child's illness', PeerJ, 4, pp. 1-24. doi: 10.7717/peerj.1662.

Gachanja, G., Burkholder, G. J. and Ferraro, A. (2014) 'HIV-positive parents, HIV-positive children, and HIV-negative children's perspectives on disclosure of a parent's and child's illness in Kenya', PeerJ, pp. 1-22. doi: 10.7717/peerj.486.

Geiselhart, K., Gwebu, T. D. and Krüger, F. (2008) 'Children, Adolescents and the HIV and AIDS Pandemic: Changing Inter-Generational Relationships and Intra-Family Communication Patterns in Botswana Introduction: The Social Impact of HIV and AIDS on Families and Children', Children, Youth and Environments, 18(1), pp. 99-125.

Hays, S. (1996) The Cultural Contradictions of Motherhood. New Haven: Yale University Press.

Hochschild, A. R. (1979) 'Emotion Work, Feeling Rules, and Social Structure', American Journal of Sociology, 85(3), pp. 551-575. doi: 10.1086/227049.

Hochschild, A. R. (1983) The Managed Heart: Commercialization of Human Feeling. Berkeley, 
CA: University of California Press.

Hondagneu-Sotelo, P. and Avila, E. (1997) 'I'm here but I'm there:The meaning of Latina transnational motherhood', Gender and Society, 11(5), pp. 548-571.

Jamaican Ministry of Health (2014) Jamaica: Country Progress Report (Global AIDS Response Progress Report). Kingston.

Krauss, B. J., Letteney, S., De Baets, A. J., Baggaley, R. and Okero, F. A. (2012) 'Caregiver's HIV disclosure to children 12 years and under: A review and analysis of the evidence', AIDS Care:

Psychological and Socio-medical Aspects of AIDS/HIV, iFirst, pp. 1-15. doi: 10.1080/09540121.2012.712664.

Kyaddondo, D., Wanyenze, R. K., Kinsman, J. and Hardon, A. (2013) 'Disclosure of HIV status between parents and children in Uganda in the context of greater access to treatment', Sahara J, 10(SUPPL.1). doi: 10.1080/02664763.2012.755323.

Leo-Rhynie, E. A. (1996) 'Class, Race, and Gender Issues in Child Rearing in the Caribbean', in Roopnarine, J., L., and Brown, J. (ed.) Caribbean Families: Diversity among Ethnic Groups,. Greenwich, CT: Ablex.

Letteney, S. (2006) 'Mothers' disclosure of maternal HIV status to children: key psychosocial correlates.', Journal of HIV/AIDS \& Social Services. Taylor \& Francis Ltd, 5(1), pp. 67-84.

Leve, M., Rubin, L. and Pusic, A. (2011) 'Cosmetic surgery and neoliberalisms: Managing risk and responsibility', Feminism \& Psychology, 22(1), pp. 122-141. doi: 10.1177/0959353511424361.

Lupton, D. (2011) “"The best thing for the baby”: Mothers' concepts and experiences related to promoting their infant's health and development.', Health Risk Soc., 13, pp. 637-651.

Madiba, S. and Matlala, C. (2012) 'Disclosure of Parental HIV Positive Status: What, Why, When, and How Parents Tell Their Children in the Era of HAART in South Africa', World Journal of AIDS, 2, pp. 194-202. doi: 10.4236/wja.2012.23025.

Moore, A., Kalanzi, D. N. and Amey, F. K. (2008) 'To disclose or not to disclose? Lower class parents living with HIV/AIDS in Lome, Togo', International Journal of Sociology and Social Policy, 28(9/10), pp. 351-364. doi: 10.1108/01443330810900194.

Mullings, B. (1999) 'Insider or outsider, both or neither: some dilemmas of interviewing in a crosscultural setting.', Geoforum, 30(4), pp. 337-350.

Muparamoto, N. and Chiweshe, M. K. (2015) "'Managing identities" and parental disclosure of HIV sero-status in Zimbabwe', African Journal of AIDS Research, 14(2), p. 145-152,.

Obermeyer, C. M., Baijal, P. and Pegurri, E. (2011) 'Facilitating HIV disclosure across diverse settings: A review.', American Journal of Public Health, 101(6), pp. 1011-1023. doi:

10.2105/AJPH.2010.300102.

PAHO/WHO (2010) Jamaica Country Cooperation Strategy 2010 - 2015.

Palin, F. L., Armistead, L., Clayton, A., Ketchen, B., Lindner, G., Kokot-Louw, P. and Pauw, A. (2009) 'Disclosure of maternal HIV-infection in South Africa: Description and relationship to child functioning', AIDS and Behavior, 13(6), pp. 1241-1252. doi: 10.1007/s10461-008-9447-4.

Parrenas, R. (2001) Servants of Globilization. Stanford: Stanford University Press.

Phoenix, A. (2010) 'Transforming "non-normative" motherhood: Retrospective accounts of transnational motherhood in serial migration', Radical Psychology, 9(2).

Pollard, V. (2013) 'Mothering and Migration:The Ones They Left Behind', in Silva, D. S. and A. S. 
A. J. (ed.) Feminist and Critical Perspectives on Caribbean Mothering. New Jersey: Africa World Press.

Qiao, S., Li, X. and Stanton, B. (2011) 'Disclosure of parental HIV infection to children: A systematic review of global literature', AIDS and Behavior, pp. 369-389. doi: 10.1007/s10461-0110069-x.

Rochat, T. J., Arteche, A. X., Stein, A., Mitchell, J. and Bland, R. M. (2015) 'Maternal and child psychological outcomes of HIV disclosure to young children in rural South Africa: the Amagugu intervention.', AIDS, 29 Suppl 1(March), pp. S67-79. doi: 10.1097/QAD.0000000000000668.

Rochat, T. J., Arteche, A. X., Stein, A., Mkwanazi, N. and Bland, R. M. (2014) 'Maternal HIV disclosure to young HIV-uninfected children', AIDS. Lippincott Williams \& Wilkins, 28(3), pp. S331-S341. doi: 10.1097/QAD.0000000000000333.

Rochat, T. J., Bland, R., Coovadia, H., Stein, A. and Newell, M.-L. (2011) 'Towards a familycentered approach to HIV treatment and care for HIV-exposed children, their mothers and their families in poorly resourced settings', Future Virology, 6(6), pp. 687-696. doi: 10.2217/fvl.11.45.

Rochat, T. J., Mitchell, J., Lubbe, A. M., Stein, A., Tomlinson, M. and Bland, R. M. (2017) 'Communication about HIV and death: Maternal reports of primary school-aged children's questions after maternal HIV disclosure in rural South Africa', Social Science and Medicine, 172, pp. 124-134.

Rochat, T. J., Mitchell, J., Stein, A., Mkwanazi, N. B. and Bland, R. M. (2016) 'The Amagugu intervention: a conceptual framework for increasing HIV disclosure and parent-led communication about health among HIV-infected parents with HIV-uninfected primary school-aged children', Front. Public Health 4:183., 4, p. 183. doi: doi: 10.3389/fpubh.2016.00183.

Rochat, T. J., Mkwanazi, N. and Bland, R. (2013) 'Maternal HIV disclosure to HIV-uninfected children in rural South Africa: A pilot study of a family-based intervention', BMC Public Health, 13(1), p. 147. doi: 10.1186/1471-2458-13-147.

Russell-Brown, P. A., Norville, B. and Griffith, C. (1997) 'Child shifting: a survival strategy for teenage mothers', in Roopnarine, J. L. and Brown, J. (eds) Caribbean families: diversity among ethnic groups. Greenwich, Conn: Ablex Publishing Corporation, pp. 223-242.

Shenton, A. K. and Hayter, S. (2004) 'Strategies for gaining access to organisations and informants in qualitative studies', Education for Information. IOS Press, 22, pp. 223-231.

Silva, D. S. and Alexander, S. A. J. (2013) Feminist and Critical Perspectives on Caribbean Mothering. Trenton, New Jersey: Africa World Press.

Sin, S. (2010) 'Considerations of Quality in Phenomenographic Research', International Journal of Qualitative Methods, 9(4).

Smith, J. A. (1996) 'Beyond the divide between cognition and discourse: using Interpretative Phenomenological Analysis in health psychology', Psychology and Health, 11, pp. 261-271.

Smith, J. A., Flower, P. and Larkin, M. (2009) Interpretative Phenomenological Analysis: Theory, Method and Research. London: Sage. doi: 10.1080/14780880903340091.

Smith, J. and Osborn, M. (2003) 'Interpretive phenomenological analysis', in Smith, J. A. (ed.) Qualitative psychology: A practical guide to research methods. London: Sage, pp. 51-80.

Tarule, M. J. (1996) 'Voices in dialogue: Collaborative ways of knowing', in Goldberger, N. R., Tarule, J. M., Clinchy, B. M., and Belenky, M. F. (eds) Knowledge, Difference, and Power: Essays Inspired by Women's Ways of Knowing. New York: Basic Books, pp. 274-304. 
Tenzek, K. E., Herrman, A. R., May, A. R., Feiner, B. and Allen, M. (2013) 'Examining the Impact of Parental Disclosure of HIV on Children: A Meta-Analysis', Western Journal of Communication, 77(3), pp. 323-339.

Tiendrebeogo, G., Hejoaka, F., Belem, E. M., Compaoré, P. L. G., Wolmarans, L., Soubeiga, A. and Ouangraoua, N. (2013) 'Parental HIV disclosure in Burkina Faso: Experiences and challenges in the era of HAART', SAHARA-J: Journal of Social Aspects of HIV/AIDS, 10(sup1), pp. S46-S59. doi: 10.1080/02664763.2012.755334.

Tompkins, T. L. (2007) 'Disclosure of maternal HIV status to children: To tell or not to tell ... That is the question', Journal of Child and Family Studies, 16(6), pp. 773-788. doi: 10.1007/s10826006-9124-z.

WHO (2011) Guideline on HIV Disclosure counselling for children up to 12 years of age. Geneva.

Wiener, L., Mellins, C. A., Marhefka, S. and Battles, H. B. (2007) 'Disclosure of an HIV diagnosis to children: history, current research, and future directions.', Journal of developmental and behavioral pediatrics : JDBP, 28(2), pp. 155-66. doi: 10.1097/01.DBP.0000267570.87564.cd.

Wiener, L. S., Battles, H. B. and Heilman, N. E. (1998) 'Factors associated with parents' decision to disclose their HIV diagnosis to their children.', Child Welfare, 77(2), pp. 115-135. 